García Gómez, T. (2019). ¿Qué profesional de la educación para qué escuela y para qué sociedad? Revista Electrónica Interuniversitaria de Formación del Profesorado, 22(3), 219-231.

\title{
¿Qué profesional de la educación para qué escuela y para qué sociedad?
}

\author{
Teresa García Gómez \\ Universidad de Almería
}

\section{Resumen}

Este artículo, resultado de la revisión y reflexión teórica, responde a la pregunta que todo profesional de la educación debería formularse: qué ser humano se desea formar para qué sociedad. Si aspiramos a una sociedad más justa y más humana, una sociedad convivencial, constituida por sujetos libres y emancipados, que es el planteamiento de este trabajo, necesitamos formar docentes, desde la pedagogía crítica, como agentes de cambio e intelectuales transformadores para que contribuyan al desarrollo de escuelas democráticas. Es decir, docentes que configuren un currículum contrahegemónico en el marco de una organización participativa en colaboración con la comunidad, instancias y movimientos sociopolíticos.

\section{Palabras clave}

Pedagogía crítica; escuela democrática; justicia social; sociedad convivencial.

\section{What education professional for what school and for what society?}

\begin{abstract}
This article, resulting from theoretical review and reflection, answers the question that every education professional should ask themselves: what human being is to be trained for what society. If our ambition is for a fairer and more humane society, a convivial society made up of free and emancipated subjects, which is the approach of this work, there is a need to train teachers, from critical pedagogy, as agents of change or transformative intellectuals so that they help towards the development of democratic schools. That is to say, teachers who shape a counterhegemonic curriculum in the context of a participatory organisation in collaboration with the community, authorities and sociopolitical movements.
\end{abstract}

\section{Key words}

Critical pedagogy; democratic school; social justice; convivial society.

\section{Contacto:}

Teresa García Gómez, tgarcia@ual.es, Universidad de Almería. Facultad de Ciencias de la Educación. Departamento de Educación. Ctra. Sacramento, s/n. La Cañada de S. Urbano, 04120-Almería (España). 


\section{Introducción}

Hay una pregunta de obligada formulación en el campo de la educación: qué ser humano queremos formar para qué sociedad o, lo que es lo mismo, qué escuela queremos construir para qué sociedad. ¿Para la sociedad existente? Una sociedad con un sistema productivo sustentado y generador de explotación y miseria, que distribuye desigualmente la riqueza; que nos conduce a la hecatombe final por la destrucción medioambiental; con desigualdades sociales; con una biopolítica en contra de la propia vida y dignidad... O ¿para otra sociedad? Una sociedad que defiende los bienes comunes, el procomún, la justicia y la democracia radical.

Educar para esta otra sociedad requiere educar un ser humano nuevo (Freire 1998; Gutiérrez, 1984), sujeto, creador de su historia y no objeto de ella. Esta concepción del ser humano debe impregnar cualquier proyecto educativo, considerando todas las dimensiones $y$ potencialidades del ser $y$

asentarse en sus posibilidades reales y en la comprensión de su específica situación en el mundo. El hombre posible arranca del hombre real con todas sus contradicciones y peculiaridades de su aquí y ahora. [...] [para] la conquista de "un hombre cada vez más hombre" y de "una vida humana cada vez más humana" (Gutiérrez, 1984, p. 71).

Los tres rasgos que caracterizarían a este ser humano nuevo, según Gutiérrez (1984, p. 72 y ss.), son estar en: un proceso de concientización permanente a través del cual conoce críticamente la realidad, las problemáticas del contexto en el que está inserto, que le permitirá transformarla al tiempo que se transforma él en ella; un proceso de humanización y de creación permanente en el marco de un proyecto planetario, imaginando futuros que pongan fin al "crecimiento salvaje", a "la sociedad del despilfarro"; y un proceso de liberación política -plena participación en los asuntos públicos-, histórica -superación de las alienaciones que imposibilitan ser más (Freire, 1975)-, y social -supresión de las injusticias, la explotación y la violencia institucionalizada- (Gutiérrez, 1984, p. 92), en el que desarrolle toda la capacidad y potencialidad para crear y desarrollar una sociedad justa y democrática para que todas las personas tengan la oportunidad real y efectiva de satisfacer las necesidades básicas y el disfrute de los bienes comunes.

La formación de este ser humano nuevo requiere de profesionales de la educación preparados para actuar como agentes de cambio social, intelectuales transformadores y activistas públicos (Giroux, 1990; Kincheloe, 2008; Huerta-Charles, 2008) en la construcción de una sociedad justa y radicalmente democrática. Para ello tienen que comprender críticamente el mundo en el que vivimos y la contribución del orden escolar dominante a este, emancipar su pensamiento y acción, tomando conciencia de a qué patrones responde y desvelando lo oculto, para actuar críticamente en las escuelas para la transformación de estas y de la sociedad, ligando la educación con la justicia social y la democracia. No pensamos que las escuelas por si solas puede crear este nuevo orden social sin un trabajo coordinado con otras instancias y movimientos sociales, pero la contribución de la educación a este cambio comienza con docentes que reflexionan sobre qué tipo de educación puede contribuir a que el alumnado desarrolle las competencias necesarias para una ciudadanía activa y participativa en la construcción de este orden social justo y democrático y con la capacidad de transformar sus condiciones sociales, políticas y económicas (Weiner, 2008 p. 102), con un profesorado que potencia y desarrolla la conciencia crítica de su alumnado para que pueda interpretar el mundo que le rodea y actuar en consecuencia (Bartolomé, 2008). 


\section{¿Qué profesional? La formación inicial en el marco de la pedagogía crítica}

Consideramos la educación como un acto político. Es un campo de lucha en torno al contenido, la forma y los objetivos de la educación, "es una de las principales áreas donde se definen los recursos, el poder y la ideología en relación con la política, la financiación, el currículum, la pedagogía y la evaluación" (Apple, 2002, p. 52). En este sentido, las escuelas pueden hacer, $y$ de hecho algunas hacen muchas otras cosas, no todas son instrumentos de dominación, por ello son espacios de lucha (Apple, 2004).

En esta línea está la idea de lo político en Freire cuando expone que toda práctica educativa implica una teoría, más o menos implícita, en relación a la visión del ser humano y de mundo que tenga el educador, y esta visión orienta el proceso educativo, que a su vez orienta al ser humano en el mundo y con otros seres. Por tanto, para Freire (1975) el acto político de la educación es el proceso de orientación del propio proceso educativo, y este no es neutral sino que tiene unos objetivos. De ahí que hable de la politicidad de la educación, la cualidad, como señala Freire (2005, p. 33), que tiene la educación de ser política. Por tanto, la discusión y el análisis está en saber de qué política se trata, es decir, la educación a favor de qué y quién o quiénes actúa, o lo que es lo mismo en contra de qué y de quién o quiénes actúa. Esta es la direccionalidad del acto político de la educación, que puede tomar dos caminos posibles: la educación como instrumento de dominación o la educación como instrumento para la emancipación. Esto apunta al mismo tiempo a la relación entre educación y poder, a la relación entre conocimiento -como construcción social- e intereses sociales, económicos, políticos y culturales (Giroux, 2003). Esto permite producir y usar el conocimiento para la emancipación o para la dominación, es decir, utilizarse y analizarse críticamente o irreflexivamente, legitimando los intereses sociopolíticos y económicos hegemónicos.

Port tanto, todo proyecto educativo es un proyecto político, por ello todo programa de formación inicial del profesorado estará enmarcado para potenciar un modelo u otro de escuela. Es decir, formaremos a futuros maestros y maestras para integrarse en el orden escolar y social actual o los formaremos para enfrentarse de forma crítica a la realidad con el objetivo de transformarla (Liston y Zeichner, 1997). En definitiva, un programa de formación comprometido con el mantenimiento o bien con el cambio de los modelos cultural, social, político, económico y escolar. En esta segunda opción se sitúa la pedagogía crítica, que coloca al ser humano en el centro del pensamiento y de las acciones para formar al profesorado como agente activo y comprometido éticamente en la construcción de una sociedad justa, una sociedad basada en una ética de la humanización y solidaridad y no en una ética del mercado (Freire, 2001; Huerta-Charles, 2008). De ahí su preocupación por los colectivos oprimidos, dominados, excluidos e invisibilizados, de ahí su denuncia de aquellas experiencias educativas que perpetúan y legitiman estos estados de dominación, de ahí su compromiso por transformar la educación, que no puede estar al margen de las estructuras económicas, políticas y sociales que envuelven a la escuela y que generan dicha dominación.

La pedagogía crítica es defensora explícita de la naturaleza política de la educación y tiene como objetivo la emancipación de los sujetos. Para ello se centra en primer lugar en la compresión de los mecanismos de opresión y dominación para su posterior transformación. En este sentido debe entenderse la pedagogía crítica como parte de un proyecto ético y político más amplio vinculado, al desarrollo de la justicia social y económica y con la construcción de una democracia radical. De ahí que uno de los primeros y grandes objetivos de la pedagogía crítica sea concientizar a los individuos, pensar el mundo en el que vivimos, pensarlo críticamente, cuestionando concepciones, asunciones y prácticas, así como las consecuencias de ellas. 
Para ello el currículum de formación del profesorado debe diseñarse y desarrollarse como una forma de política cultural, es decir, un currículum que hace de lo social, lo cultural, lo político y lo económico categorías esenciales para la comprensión de la escuela actual (Giroux y McLaren, 1990, p. 256), que posibilita al profesorado el cuestionamiento de los discursos educativos oficiales y las prácticas de dominación tradicionales dentro y fuera de la escuela, yendo más allá del lenguaje de la crítica, construyendo un lenguaje de la posibilidad (Freire, 1997; Giroux y McLaren, 1990, p. 256). Este lenguaje es el de evidenciar la existencia o crear otras prácticas docentes alternativas exentas de dominación dentro y fuera de la escuela. Estos lenguajes -el de la crítica y el de la transformación- según Giroux y McLaren (1990, pp. 256-257), implican la creación en los programas de formación del profesorado de un nuevo espacio público sustentado en la práctica democrática radical, en la libertad y la justicia social. Esto requiere formar a los futuros profesionales de la educación como intelectuales críticos capaces de afirmar y de practicar el discurso de la libertad y de la democracia (Giroux y McLaren, 1990 p. 245) en el proceso de adquirir una conciencia individual y colectiva para la creación de un espacio contrapúblico democrático (Giroux y McLaren, 1990), en el que esté presente las voces del estudiantado y de la comunidad, en el que se pueda discutir críticamente el conocimiento, generarlo, aprehenderlo y adquirir las habilidades necesarias para vivir una verdadera democracia en interés de una comunidad justa y con el objetivo de desarrollar una pedagogía liberadora. Para este objetivo es necesario atender a los problemas relativos a las experiencias concretas de la vida diaria. Problemas en conexión con lo social, lo económico y lo político y que el profesorado debe comprenderlos con el objeto de desarrollar la conciencia social. Por tanto, es un currículum basado en problemas y en conexión con el ámbito comunitario.

La pedagogía crítica entiende la enseñanza como una actividad problematizadora para la emancipación individual y colectiva, inserta en un campo de luchas por la justicia y la igualdad a través de procedimientos educativos democráticos en conexión con otros ámbitos y movimientos sociales. Desde el marco de esta pedagogía

la escuela y la educación del profesor son elementos cruciales en el proceso de consecución de una sociedad más justa. Para ello, la escuela debe proponerse como objetivo prioritario cultivar la capacidad de pensar críticamente sobre el orden social. El profesor es considerado como un intelectual transformador, con un claro compromiso político de provocar la formación de la conciencia de los ciudadanos en el análisis crítico del orden social de la comunidad en que viven. El profesor es a la vez un educador y un activista político, en el sentido de intervenir abiertamente en el análisis y debate de los asuntos públicos, así como por su pretensión de provocar en los alumnos el interés y compromiso crítico con los problemas colectivos (Pérez Gómez, 1992, p. 423).

La pedagogía crítica entiende la formación del profesorado como praxis, sustentada en los principios de democracia, justicia, igualdad y autonomía, de orientación crítica reflexiva y comprometida desde un punto de vista sociopolítico para que pueda contribuir al proceso de mejora de la enseñanza y al cambio social (Beyer, 1988 citado por Liston y Zeichner, 1997, p. 57). Una formación en el marco de la reflexión crítica para que los futuros docentes pueden empezar a identificar las relaciones que existen entre el aula y las condiciones educativas, sociales, económicas y políticas más amplias que influyen en la práctica del aula y la determinan. Esto hace necesario un enfoque de formación inicial sustentado en la dialéctica teoría-práctica, pensamiento-acción, prácticas y currículum de formación, que supere la separación y disociación entre escuela y universidad, entre escuela-comunidad-universidad. 
Un programa de formación inicial en el marco de la pedagogía crítica debe estar diseñado para:

a) Discutir de forma activa la relación que las escuelas mantienen con el orden social imperante, con las múltiples formas de dominación -género, clase social, orientación sexual...-, que permita que el alumnado desarrolle una perspectiva crítica con las relaciones asimétricas de poder que se llevan a cabo en ellas (Bartolomé, 2008), mostrando a su vez discursos y prácticas contrahegemónicas capaces de transformar las relaciones de dominación y opresión. Explicitar y analizar las relaciones entre la ideología y el poder dominantes y la cultura escolar.

b) Buscar y experimentar la relación teoría-práctica, conectando los aprendizajes con el cambio escolar y social, estableciendo conexiones entre educación liberadora y un mundo mejor (Giroux, 2008).

c) El compromiso y la responsabilidad en la construcción de escuelas democráticas y para un futuro más justo en lo escolar y en lo social.

d) La emancipación crítica, de manera que las personas puedan conseguir el poder ${ }^{1}$ para controlar sus propias vidas, en el proceso de construcción y desarrollo de una democracia radical.

e) La producción cultural alternativa en conexión con otros proyectos y movimientos sociales y populares que defienden prácticas antirracistas, antisexistas, anticlasistas, antihomófobas y anticapitalistas (McLaren y otros, 2004 citados por Weiner, 2008, p. 99), que hagan posible la emancipación de los individuos y colectivos.

f) Desarrollar un imaginario crítico y creativo en los que proyectar nuevas teorías y acciones, entendiendo la imaginación como "el acto de ver lo que todavía no está ahí, especulando sobre cómo podría ocurrir, rescribiendo lo que ha venido antes y abriéndose paso a través de "lo real"; es pensar lo improbable como posible" (Aronowitz y Bratsis, 2006 citados por Weiner, 2008, pp. 90-91). Este imaginario crítico permitirá pensar y ensayar acciones que se dirijan de forma efectiva y colectiva a la conquista de espacios de libertad, explorando nuestro estar en el mundo.

g) El aprendizaje dialógico, para indagar en las causas de la opresión y dominación y actuar en las relaciones de poder y estructuras que las provocan.

h) Una educación de la descolonización en igualdad para la emancipación, la soberanía y el equilibrio.

Finalmente, la respuesta a la pregunta ¿qué profesional? sería un profesional de la educación que asume la enseñanza como un trabajo intelectual, comprometido con la trasformación de la realidad y con la creación de nuevas posibilidades de aprendizaje; y que entiende la enseñanza como un acto político, por lo que al mismo tiempo es un educador y un activista político, que interviene abiertamente en el análisis y debate de los asuntos públicos, con el objeto de provocar en el alumnado el interés y compromiso crítico con los problemas colectivos (Pérez Gómez, 1995, p. 351). Un profesional que como intelectual creará las condiciones necesarias para que las experiencias del alumnado sean educativas, por tanto, prestará atención a ellas y hacia dónde se dirigen (Dewey, 2004, p. 45), puesto que las acciones futuras están en relación directa con las acciones que se llevan a cabo o no en el presente y reflexionará buscando las relaciones y conexiones entre lo que se trata de hacer y lo que ocurre, entre los hechos y sus consecuencias. Por tanto, desarrolla la reflexividad de

\footnotetext{
${ }^{1}$ Entendido como potencia, según Spinoza. El poder como la capacidad para producir cualquier cambio o resistirse a él (Lukes, 2007), y también como el poder con...
} 
la enseñanza (Grundy, 1998) para la concientización a través de la praxis desarrollada en los contextos reales en un clima de colegialidad y colaboración, necesarias para la elaboración y desarrollo de un proyecto común de escuela. Esto posibilitará que la formación continua del profesorado esté integrada en distintas comunidades -formativas, de aprendizaje, de práctica-, que entienden las relaciones de la escuela con la comunidad y sociedad de otro modo, con alta sensibilidad a las demandas de los territorios en los que está ubicada, generadora de procesos de apertura y participación tanto del alumnado y de las familias como de la comunidad. De manera que, el profesorado trabajará para que la comunidad se apropie de la escuela y la escuela de la comunidad, para que se produzca una interconexión escuela-comunidad, donde la participación de ambas es significativa en un proyecto común, teniendo como principio la justicia social, ya que tiene como fin una escuela teórico-práctica que tiene como proyecto el aprendizaje. Un aprendizaje al servicio de la comunidad, un aprendizaje que no solo transforma a quienes aprenden sino también a la comunidad, así el aprendizaje se convierte en potencia aumentada al ver el efecto transformador en el contexto más inmediato.

\section{¿Qué escuela?}

Necesitamos una escuela que tenga como proyecto intervenir en la construcción de un futuro humano mejor, un futuro colectivo y planetario, es decir, un mundo más humano, asegurando a través de sus prácticas y de la producción de conocimiento el desarrollo humano integral. Esta escuela es denominada en América Lantina como la Otra² educación.

Una escuela que asuma la tarea de educar, entendiendo que la educación "ya no consistirá en adaptar al niño al «orden» existente sino, por el contrario, colaborar para que por medio de respuestas creativas pueda resolver las contradicciones que obstaculizan la conquista de una sociedad diferente" (Gutiérrez, 1984, p. 66). Educar es posibilitar "ser más", como diría Freire, educar en el siglo XXI sería humanizar la humanidad. En palabras de Torres Santomé (2011)

educar [hoy] es preparar a niñas y niños y adolescentes para llegar a ser personas autónomas, capaces de tomar decisiones y elaborar juicios razonados y razonables, tanto sobre su conducta como sobre la de las demás personas; de dialogar y cooperar en la resolución de problemas y en propuestas de solución encaminadas a construir una sociedad más justa. Para este objetivo, toda persona educada necesita disponer de contenidos culturales relevantes, que le permitan comprender el mundo y, simultáneamente, desarrollar sus capacidades cognitivas, afectivas y sociales con las que poder sacar el mejor partido a sus derechos y deberes como ciudadano y ciudadana (p. 206).

Una ciudadanía crítica, participativa y comprometida con el desarrollo de la comunidad, entendiendo la educación "como un procedimiento constructivo para mejorar la sociedad y de comprender que aquella representa no solo un desarrollo de niños y jóvenes, sino también de la sociedad futura de la que serán elementos constitutivos" (Dewey, 1998, pp. 75-76). Una educación que será verdadera, según Dewey (1997), si forma parte de la experiencia de la vida de los niños y las niñas, partiendo, que no supeditada, de sus gustos e intereses para estimular las capacidades, entendidas no solo como habilidades, sino como un poder, una

\footnotetext{
2 En el marco de la denominada la Otra educación se desarrollan distintos proyectos, tales como: el Movimiento Sin Tierra (MTS) en Brasil, los Bachilleratos Populares (BP) en Argentina, las Escuelas Zapatistas en México, las Escuelas Libres en Chile, etc. Estos se abordarán en el Proyecto de Investigación.
} 
potencialidad -una potencia, una fuerza- (Dewey, 1998, p. 46), que les prepare para la vida futura en tanto que implica darles dominio sobre sí mismos, "capaz de comprender las condiciones bajo las cuales habrá de operar" (Dewey, 1997, p. 37). Esta preparación para el futuro no implica obviar que la escuela es una forma de vida en comunidad, que debe usar sus propias capacidades para fines sociales, por ello Dewey (1997, p. 39) afirma que "la educación es un proceso de vida y no una preparación para la vida", que la escuela debe tener presente en cada una de sus acciones y proyectos.

Distintas denominaciones ha recibido la escuela, que implican otra forma de hacer escuela, todas ellas en contraposición con la hegemónica de hoy, caracterizada por desarrollar una educación bancaria, ser selectiva, segregadora, individualista, competitiva, meritocrática y reproductora del orden social al buscar la adaptación al orden establecido. Una escuela que se piensa fuera de la estructura social, económica y política (Caballero, 2009), si bien está ligada al sistema productivo.

Entre las distintas denominaciones de escuela, que todas ellas ${ }^{3}$ asumen la tarea de educar, podemos citar: escuela educadora (Caballero, 2009), escuela comunidad o comunidad educadora, escuela ciudadana, escuela crítica y emancipadora, escuela que aprende (Santos Guerra, 2000), escuela del cuidado mutuo (Rogero, 2010), escuela inclusiva, y escuela centrífuga (Encina y Ezeiza, 2018).

Distintas calificaciones de escuela que atienden a un currículum contrahegemónico como producción cultural (Giroux, 2003; Beane, 2005), que trata de subvertir las relaciones asimétricas de poder y ser un enclave para la construcción y desarrollo de la democracia en el marco de un proyecto social cuyo objetivo es la liberación del ser humano, capaz de alcanzar mayores cuotas de libertad. Un currículum para una ciudadanía democrática, crítico -capaz de influir en las esferas de la vida social: economía, política, cultura, etc.-, flexible, humanizador, ligado a contextos y colectivos concretos, a sus problemáticas específicas, que considera el conocimiento situado y conectado con la vida real. Por tanto, deja de ser un documento para pasar a ser experiencia, pasa a ser un proyecto educativo en permanente construcción, se convierte en una hipótesis de trabajo, en un espacio social para experimentar los problemas y los valores educativos (Pérez Gómez, 1995, p. 351). Concretamente pasa a ser una experiencia educativa, entendiendo por experiencia, siguiendo a Dewey (2004, p. 37) "la totalidad de las relaciones del individuo con su ambiente", pero no debe considerarse como un evento aislado, sino "una relación entre el presente y el futuro, y una transacción entre el yo y el medio, a través de la cual ambos se transforman" (Dewey, 2004, p. 37), ya que toda experiencia tiene un aspecto activo y otro pasivo en tanto que es algo que le sucede al individuo, este actúa sobre el mundo y este actúa, a su vez, sobre el individuo, por ello, afirma el autor que la experiencia "no solo transforma al mundo y al individuo, también transforma la experiencia pasada y la futura: constituye una reconstrucción de la experiencia pasada y modifica la cualidad de las experiencias posteriores" (Dewey, 2004, p. 37). Y la experiencia es educativa cuando no limita a los individuos a esa sola experiencia ni altera o impide posteriores experiencias, sino que la experiencia presente continúa en experiencias subsiguientes, lo que Dewey (2004) denomina el "continuum experiencial", es decir, que toda experiencia recoge algo de la anterior y modifica en algún modo la cualidad de la posterior. Por tanto, la educación es una constante reorganización o reconstrucción de la experiencia (Dewey, 2004, pp. 73-74), que le da sentido a esta, tanto personal como social, y que aumenta la capacidad para dirigir el curso de la subsiguiente experiencia. Es un currículum que educa para la significación (Gutiérrez y Prieto, 2002, p. 38), es decir, para relacionar y contextualizar experiencias y

\footnotetext{
${ }^{3}$ Tenemos ejemplos de ellas, sirva de referencia el CEIP Trabenco, Escuela Libre de Paideia, O Pelouro, CEIP La Navata, el CEIP Nuestra Señora de Gracia, École Vitruve, Sudbury Valley School, etc.
} 
discursos, así como para dotar de sentido las prácticas de la vida cotidiana. Desarrollar esta capacidad de dar sentido, de significar el mundo y la propia experiencia, permite desarrollar también la capacidad de criticar los sentidos y los sinsentidos ajenos. Es en esta significación cuando el aprendizaje de un contenido de enseñanza puede considerarse educativo en tanto que permite pensar sobre el conocimiento cotidiano y posibilita problematizar la experiencia (Feito, 2006, p. 10). Los contenidos de la enseñanza no giran en torno a las disciplinas lengua, matemáticas, ciencias, etc.-, estas no son el centro sobre el que gira el acto de enseñar y el acto de aprender. El centro son las experiencias del alumnado, como hemos señalado anteriormente, y las disciplinas se integrarán a partir de estas y en la medida que permitan interpretar y controlar la experiencia ya poseída (Dewey, 1997). Por tanto, el conocimiento disciplinar es sustituido por el conocimiento integrado (Beane, 2005), trabajando a partir de problemas, inquietudes y cuestiones significativas extraídas de la vida del alumnado, lo cual permite la relación de los saberes y la comprensión crítica de la realidad, el aprendizajes significativo y relevante, a través de problemas, temas sociales o de interés para el alumnado y cuestiones de la vida práctica y diaria.

Dichas experiencias están afectadas por los distintos problemas de la sociedad, por tanto el currículum los incorpora para tomar conciencia sobre ellos, sobre las condiciones de existencia de los seres humanos, indagando los porqués de la opresión y de la marginalidad, incluyendo el conocimiento del poder y su funcionamiento (Giroux, 2003); así como el análisis de las prácticas de dominación, opresión y exclusión que conforman nuestra vida cotidiana. De esta forma, el currículum parte de las problemáticas, necesidades e intereses del alumnado para analizar sus propias relaciones y experiencias vividas cotidianas, de sus contextos inmediatos, ya que para que el conocimiento llegue a ser crítico, tiene que convertirse en primer lugar en significativo y relevante (Giroux, 2003, p. 165). Además, integra la cultura popular, el conocimiento "subordinado" y sus distintas expresiones producidas desde los márgenes, estableciendo nuevas formas de sociabilidad, posibilitando que el alumnado trabaje conjuntamente en proyectos tanto en la producción de los mismos como en su evaluación (Giroux, 2003, p. 164). Es decir, el currículum es negociado y sus significados también, la voz del alumnado está presente en el qué, en el para qué y el cómo del currículum, en la elección y desarrollo de oportunidades de aprendizaje, la negociación es lo que caracteriza las relaciones (Martínez Rodríguez, 1999). La participación en proyectos permite que el alumnado intervenga en sus comunidades-barrios-ciudades, en problemáticas reales ${ }^{4}$ para contribuir al bien común. Se trata de posibilitar un aprendizaje práctico en un contexto de acción social, de introducir al alumnado en la práctica de pensar su propia práctica (Giroux, 1990, p. 78) -evaluar su propio trabajo, trabajo en grupo, aprendizaje colectivo, autodeterminación de su trabajo, aprender a controlar y decidir sus ritmos, etc.-; y de posibilitar saberes útiles, en tanto que estos los pueden transferir a otros contextos distintos al escolar (Feito, 2006).

Un currículum que rechaza la pedagogía de la respuesta y de la certeza, que en definitiva es la pedagogía de la adaptación, sino que promueve la pedagogía de la pregunta (Freire y Faundez, 2010, p. 56), que vincula esta y las respuestas a acciones realizadas o posibles acciones a realizar, es la relación entre palabra y acción, es la pedagogía de la creatividad, de la invención y reinvención, de la posibilidad.

Al mismo tiempo, las distintas formas de hacer escuela entienden que la organización de esta debe estar sustentada en una estructura para potenciar la participación democrática de la comunidad educativa y las relaciones horizontales entre todos sus miembros.

\footnotetext{
${ }^{4}$ Como en otras escuelas que tienen el compromiso de trabajar varias horas a la semana por el bien común, por ejemplo: Sudbury Valley prestan servicios a la comunidad. Aquí podría emplearse la metodología de Aprendizaje Servicio.
} 
Busca el tiempo justo para cada actividad en la realización de su contexto, por lo que gestiona el propio tiempo escolar, no solo para atender a la diversidad y ritmos de aprendizaje, sino porque el propio aprendizaje de la democracia requiere de tiempo, tiempo para pensar, para contrastar y debatir públicamente, para negociar y para revisar las decisiones. Un tiempo desacelerado para una educación lenta (Domènech, 2011), atenta al tiempo subjetivo, a las relaciones y al proceso, centrada en las prioridades y no en la urgencia, en la calidad y no en la cantidad, en un tiempo modular, centrado en los proyectos de trabajo que permite el aprendizaje globalizado.

Un tiempo que atiende a las necesidades pedagógicas del alumnado -intereses, curiosidades, ritmos de aprendizaje, conexión del trabajo escolar y su vida cotidiana, etc.-. Por tanto, el tiempo es el necesario para atenderlas, entonces hablaríamos de jornada-s de centro. Es decir, del tiempo de apertura del mismo, optando por centros abiertos -a la comunidad y la comunidad abierta a los centros-, lo que requiere de una concepción y organización diferente tanto del espacio como del tiempo, que permita que cada momento del día sea un momento propicio para el aprendizaje, de compartir conocimientos y experiencias, y de interesarse por estas y por otras. En definitiva, se trataría de atender al capital cultural y relacional de la comunidad, organizarlo y ofrecerlo en los centros de forma que posibilite al alumnado el acceso a conocimientos y experiencias significativas y relevantes. Esto se organizaría mediante acuerdos y convenios con ayuntamientos, instituciones y otros organismos sociales, siguiendo la propuesta de Ivan Illich (1974), poniendo a disposición del alumnado múltiples y diversos recursos para el autoaprendizaje -ubicados dentro y fuera de los centrosy para el aprendizaje colectivo, creando grupos de intereses, destrezas y habilidades comunes que se desean desarrollar o adquirir para lo cual se reúnen; y realizando convocatorias para compartir un interés o una actividad concreta con otra u otras personas, formando Bancos Común-es de Conocimientos -BCC- (Zemos98 $\left.8^{5}\right)$ para la transmisión libre de estos y la educación mutua. Esta jornada del centro se desarrollaría con distintos profesionales, lo que no supondría una mayor ni total permanencia del profesorado en el centro. Entre estos habría gente que crearía, organizaría y planificaría una red de recursos externos e internos del centro, eliminando el monopolio de los libros de texto-, así como listas informativas de destrezas y habilidades y convocatorias para encuentros de actividad; personas asesoras que guiarían y orientaría al alumnado, familias, etc. en el uso de los grupos de intereses; maestros y pedagogos que potenciarían el pensamiento crítico; y otras personas dispuestas a compartir habilidades, destrezas, etc.

Esta concepción y vivencia del tiempo requiere de espacios no jerarquizados, adaptables, flexibles, diversos, accesibles, polivalentes y acogedores que permitan el trabajo tanto individual como en grupos de distintos tamaños. Espacios de vida y potenciadores de aprendizajes múltiples y diversos. Tiempos y espacios que son definidos en función de las actividades y finalidades educativas y no a la inversa.

Finalmente, ante la pregunta ¿qué escuela?, la respuesta es una escuela alternativa o una escuela radicalmente democrática. En términos de Giroux (2003), una escuela constituida en esfera democrática contrapública, en la que el profesorado como intelectual transformador y en el ejercicio de su autoridad emancipatoria abrirá la educación a la discusión y participación de los diferentes grupos comunitarios, estableciendo "lazos orgánicos activos con la comunidad" (Giroux, 2003, p. 167). Esto implica reconocer a las comunidades y al alumnado que forma parte de ellas, así como vincular el aprendizaje propuesto en las escuelas y el contexto del que forma parte fuera de la escuela, en el que actúa. Es la creación de la escuela

\footnotetext{
${ }^{5}$ Se puede consultar en: http://www.zemos98.org/eduex/spip.php?article5
} 
como institución comunitaria (Giroux, 2003), en la que se vincula dialécticamente el contexto teórico con el contexto concreto (Freire, 1998).

La democracia radical como práctica pedagógica caracteriza a la escuela constituida como esfera contrapública, en la que el profesorado posibilita la experiencia de la democracia como forma de vida a todo el alumnado, ya como afirma Dewey (1998) la democracia es más que una forma de gobierno, es una forma de vida. Por tanto, la educación se entiende como producción de conocimiento y, también, de sujetos políticos (Giroux, 2003, p. 306), formando al alumnado como ciudadano crítico, capaz de gobernar y autogobernarse más que ser gobernado en el marco de una ciudadanía crítica y activa. Por tanto, la escuela se convierte en un laboratorio de ensayo, de investigación, de aprendizaje, de alfabetización crítica, de diálogo, de responsabilidad social y de creación de alternativas.

La escuela como esfera pública democrática forma parte de una red conformada por organizaciones políticas, movimientos sociales, asociaciones culturales, etc. (Martin, 2008) que colaboran y articulan proyectos alternativos, cuyas prácticas van dirigidas a potenciar a las personas, su libertad, y una sociedad justa y radicalmente democrática, una sociedad sostenible en lo humano y en lo ecológico. Por tanto, el proyecto pedagógico político de la escuela formará parte de un proyecto social global cuya meta colectiva es la liberación de los seres humanos, por ello se articulará con otros proyectos contrahegemónicos -en el ámbito de la política, la economía, la cultura, la ecología...- para la igualdad, la libertad y la justicia, que buscan potenciar a los seres humanos en el desarrollo de las capacidades necesarias para superar las ideologías y formas materiales de existencia que producen y legitiman las relaciones de dominación y opresión. Es convertir el acto pedagógico en político y el acto político en pedagógico, como afirmaba Freire (2001), el acto educativo en activador de cambio, en praxis social (Gutiérrez, 1984, p.157).

Desarrollar el proyecto de forma aislada es desconsiderar que la escuela funciona como uno de los agentes de socialización dentro de una red de instituciones más amplias, por lo que si no relacionamos el proyecto educativo con otros ámbitos de la sociedad difícilmente podremos erradicar las desigualdades por sexo, cultura, clase social, preferencias sexuales, condiciones físicas, etc. Se trata de no crear islas, es decir, proyectos de educación alternativos, que potencian los aprendizajes, la autonomía y la libertad de los individuos que en ellos participan, pero sin continuidad una vez que concluyen su paso por estos. En esta línea, Zeichner (1999) afirma que

ningún plan de organización escolar, ni ningún nivel de autonomía en la toma de decisiones para los profesores o la comunidad será, por sí mismo, suficiente para enfrentarse a las desigualdades estructurales e institucionales de nuestra sociedad que se ocultan tras los problemas educativos de las escuelas (p. 93).

Por tanto, es importante considerar que el cambio educativo puede contribuir a crear una sociedad más democrática, más justa y más humana, pero por sí solo no es suficiente para construir otro orden social, otra sociedad.

\section{¿Qué sociedad?}

Article 11. Tout être humain a le droit de construire leur propre destin.

(Raoul Vaneigem) 
Hasta aquí hemos dado respuesta a qué profesional para qué escuela. Un profesional y una escuela que contribuyan a la creación de una nueva sociedad participativa, radicalmente democrática y justa en la que pueda hacerse el ser humano nuevo (Gutiérrez, 1984), que en páginas anteriores señalábamos, en la que se pueda humanizar la vida misma. Una sociedad libre y no opresora, sin élites económicas y políticamente dominadoras (Gutiérrez, 1984), acumuladoras y explotadoras de los bienes comunes ${ }^{6}$. Una sociedad que se va constituyendo y desarrollado a través de proyectos de democracia directa.

Una sociedad del procomún, es decir, en la que a ningún individuo se le niega el uso o beneficio de los bienes comunes, aquellos que son de todas las personas y de nadie al mismo tiempo y que son esenciales tanto para el mantenimiento de la vida como para garantizar la justicia social. Bienes de los que no solo se benefician los individuos, sino que estos los mantienen y los mejoran, puesto que también son de gestión común. Una sociedad sustentada en el conocimiento de los bienes comunes.

Una sociedad convivencial (Illich, 1978) centrada en el ser y no en el tener, marcada por una relación convivencial, que "es acción de personas que participan en la creación de la vida social. Trasladarse de la productividad a la convivencialidad es sustituir un valor técnico por un valor ético, un valor material por un valor realizado" (Illich, 1978, p. 27).

Son distintos los proyectos que se dirigen hacia este tipo de sociedad participativa y convivencial. Proyectos que tendrían que dejar de ser minoritarios y extenderse en el tejido social, junto aquellos que las personas puedan crear para potenciar este tipo de sociedad. Entre estos, y a modo de ejemplo, podemos citar los Presupuestos Participativos ${ }^{7}$ para potenciar la participación directa de la ciudadanía en la gestión de las ciudades, elaborando los presupuestos públicos municipales y realizando un seguimiento de los compromisos alcanzados. Presupuestos que se elaboran atendiendo a las necesidades cotidianas y prioritarias de las ciudades correspondientes. Asimismo, esta participación implica que las personas pueden intervenir en los asuntos que atañen a su ciudad, dialogando sobre las problemáticas y necesidades, y buscando soluciones compartidas, atendiendo a dichas necesidades y deseos reales (Francés y Carrillo, 2008).

Otro proyecto para frenar el mercado y la explotación capitalista-patriarcal sería no repartir el trabajo sino la riqueza, ese es el objeto de la Renta Básica de las Iguales, que establece que toda persona por el hecho de nacer la sociedad le proporcionaría los bienes materiales para vivir con dignidad (Iglesias, 2002).

El previsible agotamiento de petróleo y de los combustibles fósiles, el cambio climático y la crisis económica presenta una serie de desafíos a los que hacen frente las ciudades en transición ${ }^{8}$, que se han organizado buscando formas de vida más sostenibles a través de un

\footnotetext{
${ }^{6}$ Tanto los del medio natural (tierra, bosques, agua y aire) como los generados en sociedad (espacio público, sanidad, educación, cultura, conocimiento, cuidados colectivos, etc.).

${ }^{7}$ Las primeras iniciativas se inician en Porto Alegre (Brasil) en 1989. Desde entonces se han ido desarrollando en otras ciudades tanto de América Latina como de Europa. En España encontramos ejemplos en Sevilla, Córdoba o Getafe (Francés y Carrillo, 2008).

${ }^{8}$ Totnes, en el condado de Devon (Inglaterra), es una comunidad de transición. En España podemos encontrar este movimiento en Coín en Transición, Red de Decrecimiento en Sevilla, La Palma Transición, etc. Para más información: https://elproyectomatriz.wordpress.com/2010/10/11/pueblos-en-transicion/ También se puede leer El manual de transición, de Rob Hopkins, fundador del movimiento.
} 
menor consumo de energía, de la producción de alimentos a escala local y comunitaria y a favor de la agroecología, la permacultura y el decrecimiento.

\section{Referencias}

Apple, M. (2002). Educar como dios manda. Barcelona: Paidós.

Apple, M. (2004). Entrevista a Michel Apple: La educación frente a la larga noche neoliberal. El Nudo de la Red, 3-4, 98-108.

Bartolomé, L. (2008). La pedagogía crítica y la educación de los profesores y profesoras: radicalización del profesorado futuro. En P. McLaren y J. Kincheloe (Eds.). Pedagogía crítica (pp. 357-390). Barcelona: Graó.

Beane, J. (2005). La integración del currículum. Madrid: Morata.

Caballero, A. (2009). ¿Qué escuela, para qué sociedad? El modelo de educación y de educador que necesitamos. En G. Romero y A. Caballero (Eds.). La crisis de la escuela educadora (pp. 41-69). Madrid: Laertes.

Dewey, J. (1997). Mi credo pedagógico. León: Universidad de León.

Dewey, J. (1998). Democracia y educación (3a ed.). Madrid: Morata.

Dewey, J. (2004). Experiencia y educación. Madrid: Biblioteca Nueva.

Domènech, J. (2011). Elogio de la educación lenta. Barcelona: Graó.

Encina, J. y Ezeiza, A. (2018). Educaciones centrífugas. En J. Encina, A. Ezeiza y E. Urteaga (Coord.). Educación sin propiedad (pp. 79-94). Navarra: Volapük.

Feito, R. (2006). Otra escuela es posible. Madrid: Siglo XXI.

Francés, F. y Carrillo, A. (2008). Presupuestos participativos. Recuperado de http://www.presupuestosparticipativos.com/files/5600-3779-

fichero/Guia\%20metodol\%C3\%B3gica\%20propia\%20de\%20los\%20Presupuestos\%20Particip ativos.pdf

Freire, P. (1975). Acción cultural para la libertad. Argentina: Tierra Nueva.

Freire, P. (1997). A la sombra de este árbol. Barcelona: El Roure.

Freire, P. (1998). La educación como práctica de la libertad (ga ed.). Madrid: Siglo XXI.

Freire, P. (2001). Pedagogía de la indignación. Madrid: Morata.

Freire, P. (2005). La educación en la ciudad (3a ed.). México: Siglo XXI.

Freire, P. y Faundez, A. (2010). Por una pedagogía de la pregunta. Valencia: Ediciones del CREC.

Giroux, H. (1990). Los profesores como intelectuales. Barcelona: Paidós.

Giroux, H. (2003). Pedagogía y política de la esperanza. Buenos Aires: Amorrotu.

Giroux, H. (2008). Introducción: democracia, educación y política en la pedagogía crítica. En P. McLaren y J. Kincheloe (Eds.). Pedagogía crítica (pp. 17-22). Barcelona: Graó. 
Giroux, H. y McLaren, P. (1990). La educación del profesorado como espacio contrapúblico: apuntes para una redefinición. En T. Popkewittz (Ed.). Formación de profesorado (pp. 244-271). Valencia: Universidad de Valencia.

Grande, S. (2008). Red Lake desconsolado. pedagogía, descolonización y proyecto crítico. En P. McLaren y J. Kincheloe (Eds.). Pedagogía crítica (pp. 431-459). Barcelona: Graó.

Gutiérrez, F. (1984). Educación como praxis política. México: Siglo XXI.

Gutiérrez, F. y Prieto, D. (2002). La mediación pedagógica. Xàtiva, Valencia: Diálogos.

Huerta-Charles, L. (2008). Pedagogía del testimonio: reflexiones sobe la pedagogía de la pedagogía crítica. En P. McLaren y J. Kincheloe (Eds.). Pedagogía crítica (pp. 340-355). Barcelona: Graó.

Iglesias, J. (2002). Las rentas básicas. Barcelona: El Viejo Topo.

Illich, I. (1974). La sociedad desescolarizada. Barcelona: Barral Editores.

Illich, I. (1978). La convivencialidad (3a ed.). Barcelona: Barral Editores.

Kincheloe, J. (2008). La pedagogía crítica en el siglo XXI: evolucionar para sobrevivir. En P. McLaren y J. Kincheloe (Eds.). Pedagogía crítica (pp. 26-69). Barcelona: Graó.

Liston, D. y Zeichner, K. (1997). Formación del profesorado y condiciones sociales de la escolarización. Madrid: Morata.

Lukes, S. (2007). El poder. Un enfoque radical (2a ed.). Madrid: Siglo XXI.

Martin, G. (2008). La pobreza de la pedagogía crítica: hacia una política del compromiso. En P. McLaren y J. Kincheloe (Eds.). Pedagogía crítica (pp. 461-483). Barcelona: Graó.

Martínez Rodríguez, J. (1999). Negociación del currículum. Madrid: La Muralla.

Pérez Gómez, Á. (1992). La función y la formación del profesor/a en la enseñanza para la comprensión. Diferentes perspectivas. En J. Gimeno y Á. Pérez Gómez. Comprender y transformar la enseñanza (pp. 398-429). Madrid: Morata.

Pérez Gómez, Á. (1995). Autonomía profesional del docente y control democrático de la práctica educativa. En AA.VV. Volver a pensar la educación. Vol. Il. Prácticas y discursos educativos (pp. 339-353). Madrid: Morata.

Rogero, J. (2010). Escuela del cuidado mutuo. Aula de Innovación Educativa, núm. 191, 59-62.

Santos Guerra, M. (2000). La escuela que aprende. Madrid: Morata.

Torres Santomé, J. (2011). La justicia curricular. El caballo de Troya de la cultura escolar. Madrid: Morata.

Weiner, Eric J. (2008). La pedagogía crítica y la crisis de la imaginación. En P. McLaren y J. Kincheloe (Eds.). Pedagogía crítica (pp. 89-116). Barcelona: Graó.

Zeichner, K. (1999). Contradicciones y tensiones en la profesionalización docente y en la democratización de las escuelas. En Á. Pérez Gómez, J. Barquín y F. Angulo (Coords.). Desarrollo profesional del docente: política, investigación y práctica (pp. 78-94). Madrid: Akal. 